\title{
Out-of-Plane Response of Infill Masonry Walls
}

Open Access

\author{
E. Vougioukas*
}

School of Civil Engineering, National Technical University of Athens, Athens, Greece

\begin{abstract}
The in-plane effect of infill walls on the structural response of reinforced concrete frames has been widely acknowledged via numerous experimental and numerical investigations and, as a result, the need to consider their effect on structural response has been acknowledged (indicated) in the latest generation of structural design codes worldwide. Due to the uncertainties concerning the behavior of masonry at the material and structural level, the latter elements are usually ignored during the structural analysis phase. They are only considered when (i) there is suspicion that their influence can be detrimental on the overall structural response or on the behavior of individual structural - loadbearing - elements or (ii) when it is necessary to justify an elevated overall load-carrying capacity of an existing frame structure. In the latter case, both the in-plane and out-of-plane behavior can potentially play significant roles in accurately determining the overall load-carrying capacity of the frame structure at hand. To date, emphasis has been placed on investigating the in-plane contribution of the infill walls on the overall structural response whereas the effect of the out-of plain behaviour of the infill walls has been less studied. Should the infill walls fail in the out-of-plane direction, then any calculations performed on the basis that they can sustain in-plane loading would be inaccurate. In the present study a model is proposed, which allows one to estimate which infill walls do not exhibit out-of-plane collapse and in doing so, continue participating in the structural model with their in-plane stiffness and bearing capacity. The predictions of the proposed analytical model are verified experimentally via shake table testing.
\end{abstract}

Keywords: Infill wall, out-of-plane loading, shaking table, acceleration, earthquake, RC frames.

\section{INTRODUCTION}

Reinforced concrete $(\mathrm{RC})$ has been widely used for the construction of the structural frames of multi-storey buildings since World War II. When designing against seismic action such buildings were considered to resist inertia loads associated with a ground acceleration equal to the maximum acceleration value recorded up to that time. During the last decades, as monitoring networks have become increasingly e dense and efficient worldwide, it has been proven that seismic acceleration imposed to buildings during medium to strong earthquakes, is actually many times larger than the design value initially considered. The fact that the majority of these structures have not collapsed after sever earthquakes leads to the conclusion that the additional seismic energy appears to have been absorbed by members considered as "non-structural" such as the infill walls. As a result, nonstructural elements are expected to sustain damage, the level of which is dependent on the amount of seismic energy they dissipate when subjected to seismic excitation. In the case of new buildings, a designer can choose among a variety of structural systems (i.e. walls or wall-equivalent dual concrete systems, braced steel or steel-concrete composite systems) in order to improve structural performance against earthquake action (EN1998-1-4.3.6.1) [1]. This allows him to neglect the interaction of the main structural elements with the masonry

*Address correspondence to this author at the School of Civil Engineering, National Technical University of Athens, Athens, Greece;

Tel: 00302107721178 ; Fax: 00302107721275 ;

E-mail: manolis@central.ntua.gr infill walls. However, when considering existing buildings (EN1998-3-5.1.3) [1] improvement of structural performance against earthquake action can be accomplished through the introduction of new structural elements (e.g. bracings or infill walls; steel, timber or reinforced concrete belts in masonry construction; etc).Alternatively, such an improvement can be also justified when considering the contribution on the non-structural members such as infill walls on the overall structural response of the RC frame by including them in the mathematical models employed for structural analysis .

\section{STATE OF THE ART}

During the last decades, when assessing structural performance of buildings after major earthquakes given to date, it has been repeatedly shown that infill walls play an important role on the overall seismic behavior of RC frame structures. Furthermore, it has become evident that, mainly for the case of older buildings, without the contribution of the infill walls many existing RC structural frames wouldn't have been able to absorb the seismic energy without sustaining significant damages or collapsing.

Despite their significant contribution to the overall loadcarrying capacity, the existing infill masonry walls are usually ignored during the structural analysis and design of the RC frame, mainly because of the absence of analytical tools capable of accurately simulating the behavior of the infill walls in the mathematical models representing the whole structure, especially for the case of seismic loading. Ignoring the contribution of existing infill masonry walls to the overall structural response is also considered to be a conservative and thus safe approach. However, in seismic regions, ignor- 
ing the frame-infill wall interaction is not always on the safe side. When considering the global response of the RC frame under lateral (i.e. seismic) loading, the contribution of infill walls can drastically change the dynamic characteristics of the structure at hand (i.e. increasing the in-plane stiffness of the frame) by acting as diagonal struts thus, magnifying substantially the response spectra values (i.e. resulting in smaller eigenperiods that correspond to larger spectral values and decreasing values of damping ratio). However, at the same time the interaction between infill walls and the frame may also cause the development of stress concentrations in certain regions of the structure (e.g. joint area) leading to localized cracking or even unexpected forms of failure, which may have a detrimental effect on the overall response of the $\mathrm{RC}$ frame.

The reason for neglecting the infill walls during the design process is partly attributed to the incomplete knowledge of the behavior of quasi-brittle materials such as unreinforced masonry (URM) and to the lack of conclusive experimental and analytical results to substantiate a reliable design procedure for this type of structures. Furthermore the available experimental data describing the behavior of the masonry infill walls are characterized by significant scatter due to the large number of parameters associated with the properties of the materials involved (concrete and masonry), the boundary conditions between of the infill frame and the structural elements of the RC frame, the lateral stiffness of the frame and the infill wall and the type of loading applied. As a result, although the available experimental data can provide a qualitative description of the behavior of masonry infill walls and their effect on the structural response of RC frames at the same time, they are unable to realistically quantify this affect. Based on the above, the inclusion of the existing infill walls in the mathematical models employed in the analysis and design stages, provides predictions of the effect of the infill wall on the overall structural behavior with a high degree of uncertainty. This is why it is not surprising that no consensus has emerged leading to a unified approach for the analysis and design of infilled frame systems, despite the more than six decades extensive experimental Smith [2]; Smith and Carter [3] Page et al. [4]; Mehrabi et al. [5]; Buonopane and White [6]; and semi-analytical investigations Liauw and Kwan [7]; Dhanasekar and Page [8]; Saneinejad and Hobbs [9]; Syrmakezis et al. [10]; Asteris [11, 12]; Moghaddam [13]; Asteris et al. [14, 15] Guney et al. [16, 17].

To date, many numerical investigations have been carried out, based mainly on the finite elements analysis method, concerned with the investigation of the effect of various parameters associated with the previously mentioned uncertainties (such as thickness, material properties and openings) on the overall structural response of infilled frames. In addition, experimental studies have been carried out on the same subject. An extensive review of research on in-plane testing and modeling of masonry infilled frames up to 1987 has been reported by Moghaddam and Dowling [18]. A comprehensive review of the relevant literature published between 1987 and 1997 has been presented by Madan et al. [19]. More updated state-of-the-art reports can be found in Crisafulli et al. [20] and, recently,
Asteris et al. [21]. However, even with this data these uncertainties have not been significantly reduced.

Based on published work by Angel et al. [22], FEMA306 [23] recommends the calculation of the capacity of masonry infill (MI) walls associated with out-of-plane failure under seismic excitation. The capacity of MI is calculated as the maximum uniform pressure that can be applied on the surface of the walls in the out-of-plane direction, and it depends on the strength of the masonry, the slenderness ratio, and damage sustained by the MI walls and the surrounding columns due to the in-plane seismic actions. Eurocode 8 [1] states that the capacity and stiffness of the infill walls should be included in the structural model (also influencing the structural irregularity), while at the same time accounting for the high uncertainties related with the behaviour of the infill walls (namely, the variability of the mechanical properties of masonry, the existence of openings, the boundary conditions of the walls, possible modifications during the use of the building). This uncertainty results to the observed variation of damaged sustained by "similar" infill walls after earthquakes. Furthermore, Eurocode 8 suggests that appropriate measures should be taken in order to avoid brittle failures and premature disintegration of the infill walls (in particular of masonry walls with openings or of friable materials), as well as the partial or total out-of-plane collapse of slender masonry walls.

The present study is concerned with the investigation of the out-of-plane response of infill frames under seismic excitation. More specifically, it investigates whether out-of-plane motion may potentially cause an infill wall to sustain significant damages or even collapse. Consequently, after a certain degree of damage, the latter element can no longer contribute to the response of the $\mathrm{RC}$ frame with its in-plane stiffness. As a result, after failure due to out of plane motion, the wall must be essentially cancelled from the mathematical model representing the structure and cannot participate in any further in the structural analysis. Such type of wall collapsemechanisms during earthquakes are presented in Photos (13), and have been investigated experimentally in the past by Carydis et al.[24], Meisl et al. [25], Liu et al. [26]. Based on the experimental observations a simplified model is presently proposed to describe the mechanism of the out-of plane collapse of infill walls and to predict under which circumstances this may occur. The proposed model of out-of plane failure can be employed in structural analysis as a failure criterion in order to appropriately cancel infill walls that have collapsed in the out-of-plane direction during static and dynamic finite element analysis of RC framed structures.

\section{PROPOSED MODEL}

The out-of-plane mode of failure of infill walls has been widely observed in frame structures after been subjected to severe earthquakes. This mode of failure can be clearly observed in Photos $(\mathbf{1}, \mathbf{2})$ and $(\mathbf{3 a})$. Furthermore, the collapse of infill walls shown in photos (3b) and (4) can be fully attributed to the out of plane mode of failure.

Considering a masonry wall (block) with height $h$ and width $t$, when subjected to a horizontal deflection $\delta$ at its top it deforms as shown in Fig. (1). Due to the horizontal deflection applied to the wall the diagonal $\Delta$ of the block is short- 
ened, from its initial value $\Delta_{\text {init }}$ to the value $\Delta_{\text {final }}$ as calculated by eqs (1) and (2) respectively

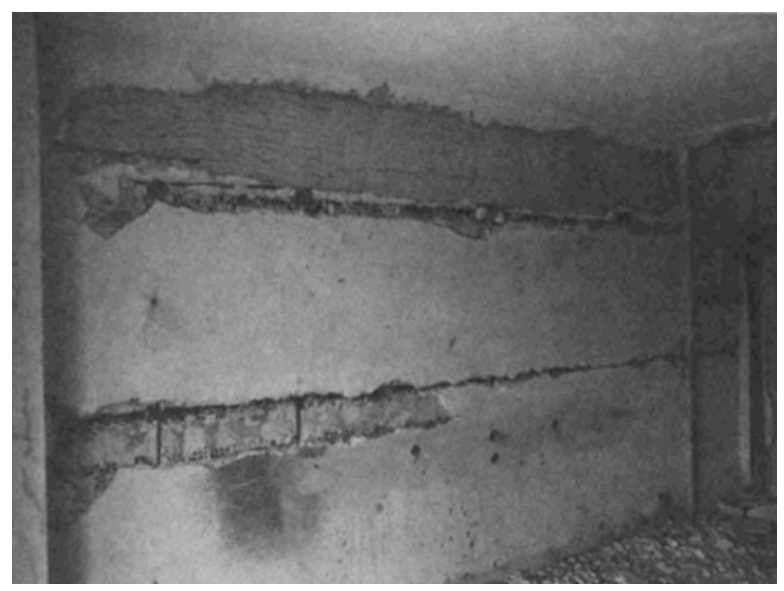

Photo (1). Horizontal cracking due to out of plane shaking of infill walls (Central Greece Earthquake, 1981) Carydis et al. [27].

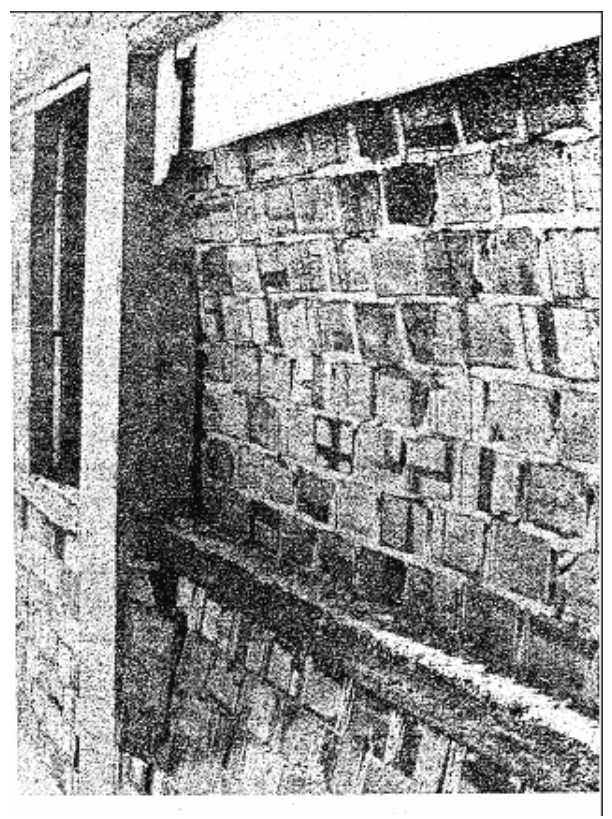

Photo (2). External wall collapse due to out of plane seismic excitation (Kalamata Earthquake, 1986).

$$
\begin{aligned}
& \Delta_{\text {initial }}=\sqrt{h^{2}+t^{2}} \\
& \Delta_{\text {final }}=\sqrt{h^{2}+(t-\delta)^{2}}
\end{aligned}
$$

As a result, the absolute value of the induced axial strain can be calculated from eqs (3) and (4)

$$
\begin{aligned}
& |\varepsilon|=\frac{\left(\Delta_{\text {init }}-\Delta_{\text {final }}\right)}{\Delta_{\text {final }}}|\varepsilon|=\frac{\Delta_{\text {initial }}-\Delta_{\text {final }}}{\Delta_{\text {final }}} \\
& \text { or, }|\varepsilon|=1-\sqrt{1+\frac{\delta(\delta-2 t)}{h^{2}+t^{2}}}
\end{aligned}
$$

In order to account for existing imperfections, due to (a) careless construction, or (b) the effect of creep of the wall or (c) induced relative deformation between ceiling and floor, a representative parameter $c$ (dimensions of length, relatively small) is considered. The inclusion of this parameter in the analysis transforms eq.(2) into eq.(5) and eq.(4) into eq.(6).

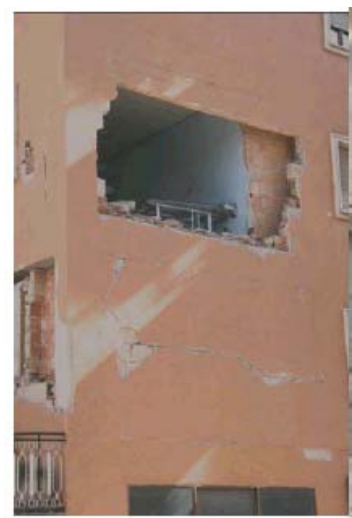

(a)

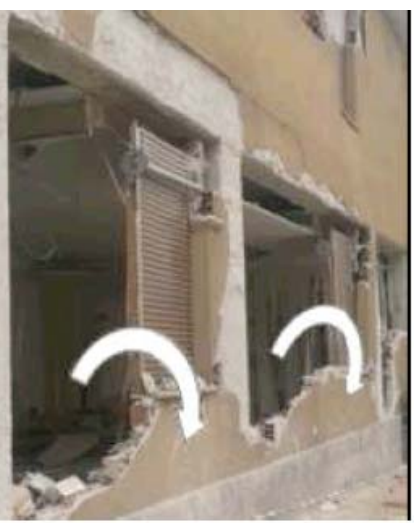

(b)
Photo (3). Out-of-plane collapse of infill walls (Abruzzo Earthquake 2009, Vicente et al. [28]).

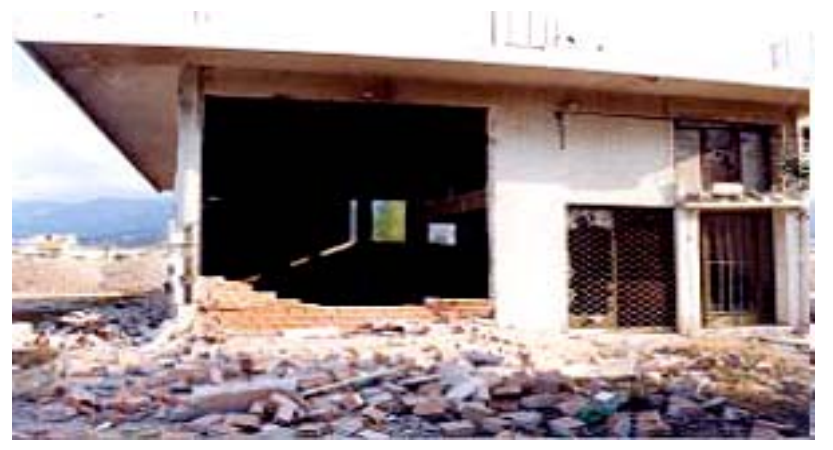

Photo (4). External wall collapse due to out of plane seismic excitation (Athens Earthquake,1999).

$$
\begin{aligned}
& \Delta_{\text {final }}=\sqrt{h^{2}+(t-\delta)^{2}}+c \\
& \text { thus, }|\varepsilon|=1-\sqrt{1+\frac{\delta \times(\delta-2 t)}{h^{2}+t^{2}}}-\sqrt{\frac{c^{2}}{h^{2}+t^{2}}}
\end{aligned}
$$

As shown if Fig. (1), the developing internal axial forces ( $\mathrm{P}$ and $\mathrm{R}$ ), acting on the upper and lower cross-sections of the block are given by the following analytical expressions:

$\mathrm{P}=\varepsilon \times \mathrm{E} \times \mathrm{t}, \mathrm{R}=\varepsilon \times \mathrm{E} \times \mathrm{t}+\mathrm{W}$

Due to the rotation (associated with the out of plane motion of the wall), a cracked and an uncracked region form at the top and bottom regions of the block shown if Fig. (1). A lower limit for the width of the non-cracked section (compressive zone) $a^{\prime}$ (bottom section) and $a$ (top section) can be calculated see Fig. (2) as follows:

$a^{\prime}=\mathrm{R} / 0.85 \times f_{c w} a=\mathrm{R} / 0.85 \times f_{c w}$

Instability, leading to collapse, will occur as the resultant force ( $\left.\mathrm{R}^{\prime}\right)$ of $\mathrm{P}$ and $\mathrm{W}$ is found to act at the outside the part of the wall, compared to the position of $\mathrm{R}$ (base of wall). (Fig. 1). 


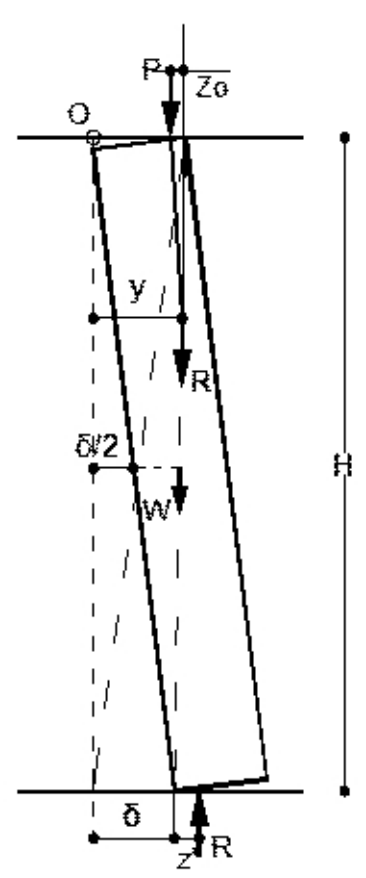

Fig. (1). Section of wall segment, subjected to differential lateral displacements at two edges $\left(\mathrm{z}_{\mathrm{o}}=\mathrm{a} / 2, \mathrm{z}^{\prime}=\alpha^{\prime} / 2\right)$. Wall has thickness $t$.

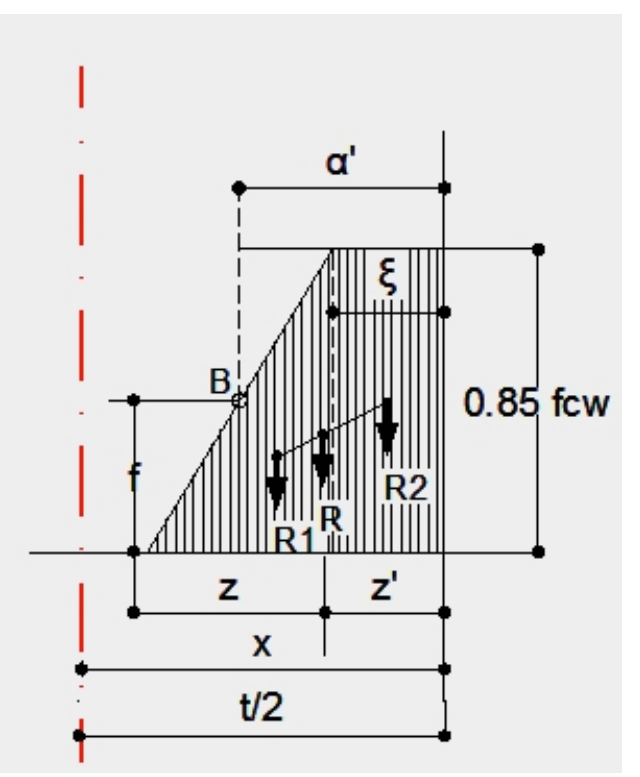

Fig. (2). Trapezoid distribution of axial stresses and determination of moment $\operatorname{arm} \mathrm{Z}$ in the lower part of the wall.

The distance $y$ of resultant $\mathrm{R}^{\prime}$ can be calculated by the moment equilibrium about the initial position $\mathrm{O}$.

$\mathrm{P} \times\left(t-\frac{\alpha}{2}\right)+W \times\left(\frac{t+\delta}{2}\right)=R \times \chi$

thus
$y=\frac{\mathrm{P} *\left(t-\frac{\alpha}{2}\right)+W *\left(\frac{t+\delta}{2}\right)}{P+W} \chi=\frac{\mathrm{P} \times\left(t-\frac{\alpha}{2}\right)+W \times\left(\frac{t+\delta}{2}\right)}{P+W}$

At the ultimate limit state of the wall, $\delta$ is set to $\delta_{\mathrm{u}}$ and $\mathrm{y}=$ $\delta_{u}+\alpha / 2$. Therefore eq.(10)can be transformed into eq.(11)

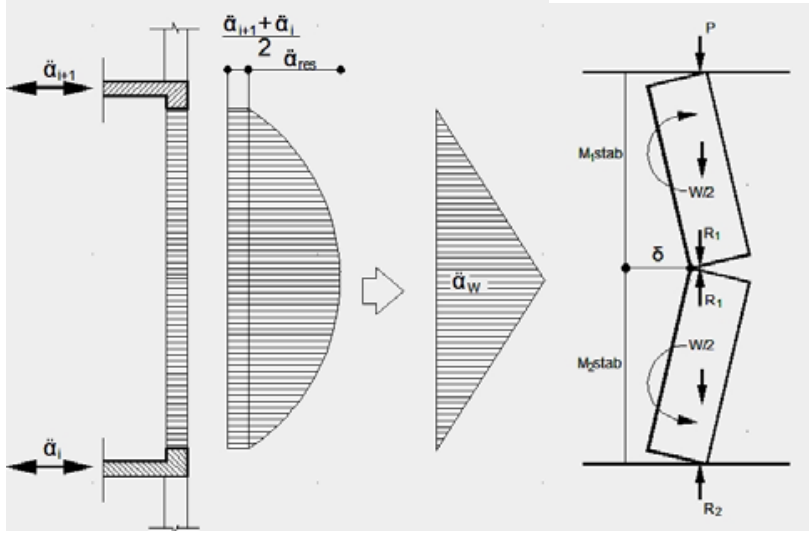

Fig. (3). (a) Simulation of out-of- plane inertial forces to an infill wall, adjacent to stories "i" and "i+1"_(b) Equilibrium of moments and vertical forces in the deformed position after tensile cracking in the middle of the wall.

$\delta_{u}=\frac{2 \mathrm{P} *\left(t-\frac{\alpha+\alpha^{\prime}}{2}\right)+W *\left(t+\delta_{u}\right)}{P+W} \delta_{u}=\frac{2 \mathrm{P} \times\left(t-\frac{\alpha+\alpha t}{2}\right)+W \times\left(t-\alpha^{\prime}\right)}{2 R-W}$

In eq. (11), $\mathrm{P}$ is also a function of $\delta$ :

$\mathrm{P}=\mathrm{f}(\delta) \times \mathrm{E} \times \mathrm{t}$

Stability moment is given by:

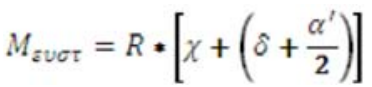

Where $\chi$ is the un-cracked depth (compressive zone) of the wall section see Fig. (5).

Solution of Eq. (11) can be achieved via the iterative procedure outlined below:

a) A value is given to $\delta_{u}$.

b) The axial strain is calculated via Eq.(6).

c) The axial strain is calculated via Eq.(7).

d) Non-cracked sections $a$ and $a^{\prime}$ are calculated via Eq.(8).

e) $\delta_{\mathrm{u}}$ is recalculated via Eqs. (11) and (12)

f) The above steps are repeated until the procedure converges.

g) After convergence the stability moment is calculated via Eq.(13)

At this stage, value of $\delta_{u}$ can be compared to the maximum, deformation limit between adjacent floors set by the Codes (e.g. 0.005 times the story height, as prescribed in EC8-Part1-4.4.4.2).

In order for the previously described model to be used for the case of the out-of-plane collapse of infill walls, as illus- 
trated in Photos (1) to (4), it needs to be slightly modified, as follows:

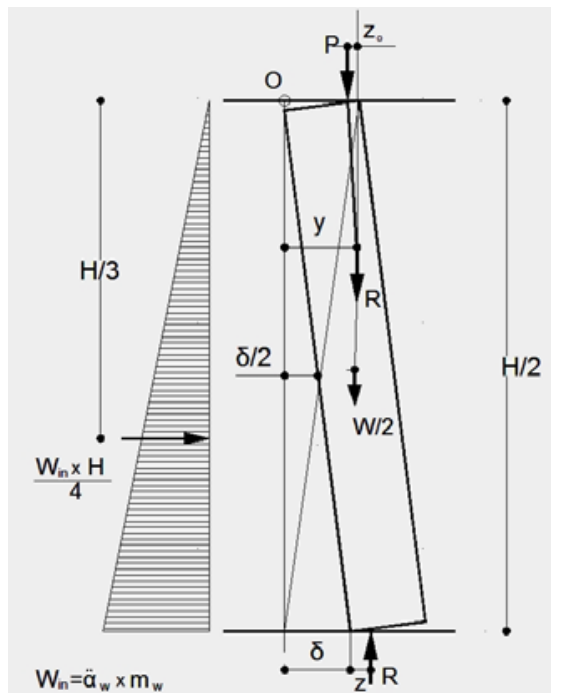

Fig. (4). Calculation of lateral forces in deformed position (upper part) for wall has with thickness $t$.

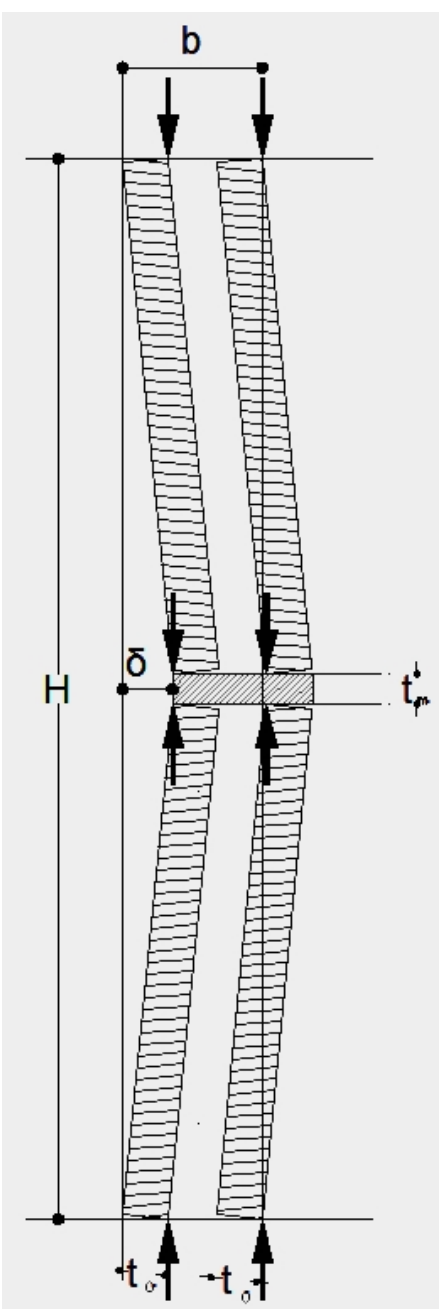

Fig. (5). Model simulation of wall constructed in two parts, due to insulation reasons (Reaction forces stabilize the wall). Wall's segment thickness $t_{\theta}$ should be used in the model, instead of $t$.
Considering the inertia forces acting in the out-of-plane direction of the wall, one can assume a linear distribution of accelerations as shown Fig. (3a). As a result, the wall deforms initially elastically until the flexure cracks form. After crack formation the model presented in Fig. (3b) can be employed which through the use of the horizontal axis of symmetry intersecting the wall at mid-height, can be simplified into the problem shown in Fig. (4).

Comparing Fig. (4). to Fig. (1) it can be clearly seen that the response of both models is governed by the same equations (1-12 above) when setting the height $h$ equal to $h / 2$ and as a result eq.(11) becomes

$\delta_{u}=\frac{2 \mathrm{P} \times\left(t-\frac{\alpha+\alpha^{t}}{2}\right)+\frac{W}{2} \times\left(t-\alpha^{\prime}\right)}{2 R-W}$

The problem that arises in the present case is that $\delta_{u} \delta_{u}$ cannot be directly compared to a specific design value, but has to be associated to the acting inertia force, which is function of the seismic acceleration imposed on the boundary regions of the wall.

When considering the moment's equilibrium about point O one obtains:

$\frac{P_{\text {seismic }} * \frac{H}{2}}{2}=\frac{2}{3} \times \frac{H}{2}+R *(\delta+z)-R * y=0$

Thus $P_{\text {seismic }}=\frac{12 * R *\left(y-\delta-z^{\prime}\right)}{H^{2}}$ [where, $\left.R=R(\delta)\right]$.

The value of $P_{\text {seism }}$ is associated to seismic acceleration $\alpha_{\text {seism }}$ as follows

$\alpha_{\text {seismic }}=\frac{P_{\text {seismic }}}{m_{\text {wall }}}$

Based on the above one can formulate the following iterative procedure:

a) From eq. (8), $a$ and $a^{\prime}$ are determined.

b) For a given value of $\mathrm{z}, \mathrm{f}_{\mathrm{c}}$ (compressive strength of the masonry) and $\ddot{\alpha}_{w}$ (the acceleration exhibited by the masonry wall at mid-height) are calculated based on Figs. (2) and (4).

c) When $f_{c}$ becomes equal to $0.85^{*} f_{w}$ then the equivalent static force $P_{\text {seism }}$ and $\ddot{\alpha}_{w}$ are calculated form eqs (15\&16).

d) After initial cracking occurs, as $\delta$ increases, the axial stress diagram is considered to transform by rotation of inclined stress line about point $\mathrm{B}$ Fig. (2).

Thus $\frac{0.85}{\chi-\xi} * f_{c w}=\frac{f}{\chi-\mathbf{a}^{\prime}}$

a) The resultant of reactions $\mathrm{R}$ is then calculated by the following equation

$R=R_{1}+R_{2}=0.85 * \frac{f_{c W} *(\chi-\xi)}{2}+0.85 * f_{c w} * \xi$

Eq.18 can be re-written in more compact form of Eq.19

$R=0.85 \times \frac{f_{c w} *(\chi+\xi)}{2}$ 


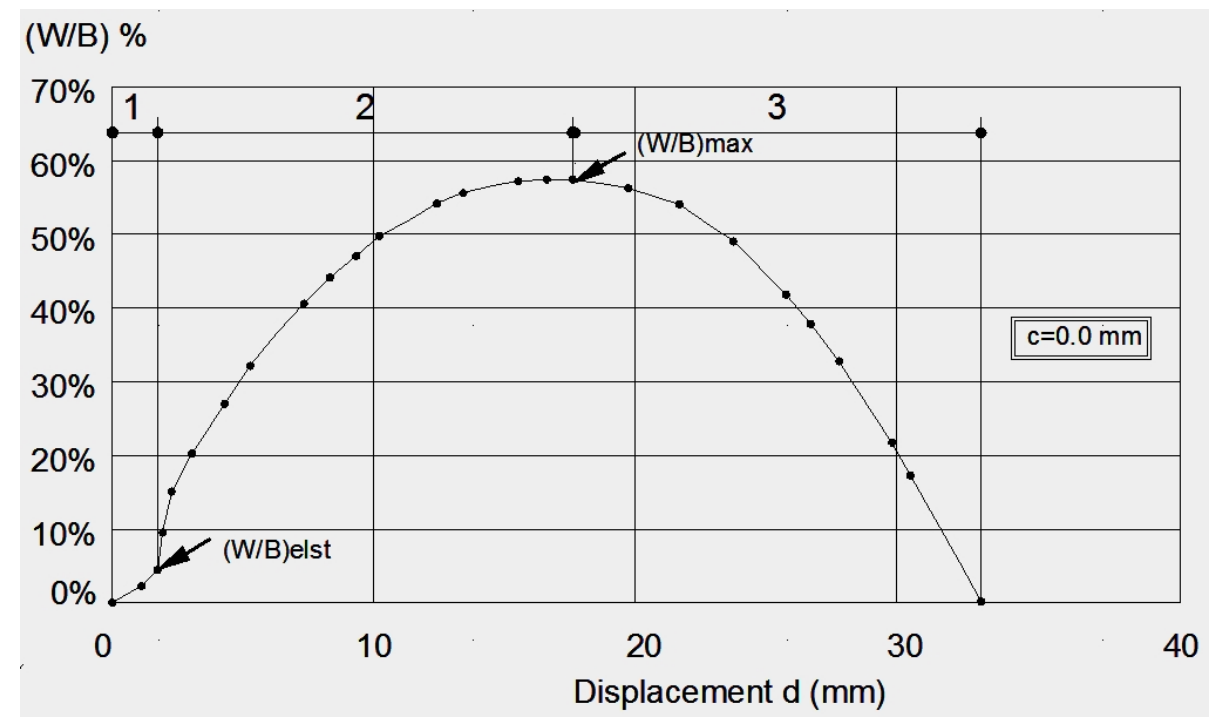

Fig. (6). Acceleration, in terms of (W/B), versus displacement $\mathrm{d}(=\delta)$ at the midde of the wall for segment thickness $8 \mathrm{~cm}$ (Region 1: elastic, Region 2: cracked, Region 3: corresponding to lateral collapse of the wall). (W/B $)_{\max }$, is a" ${ }_{w, l i m}$ for the wall Fig. (4).

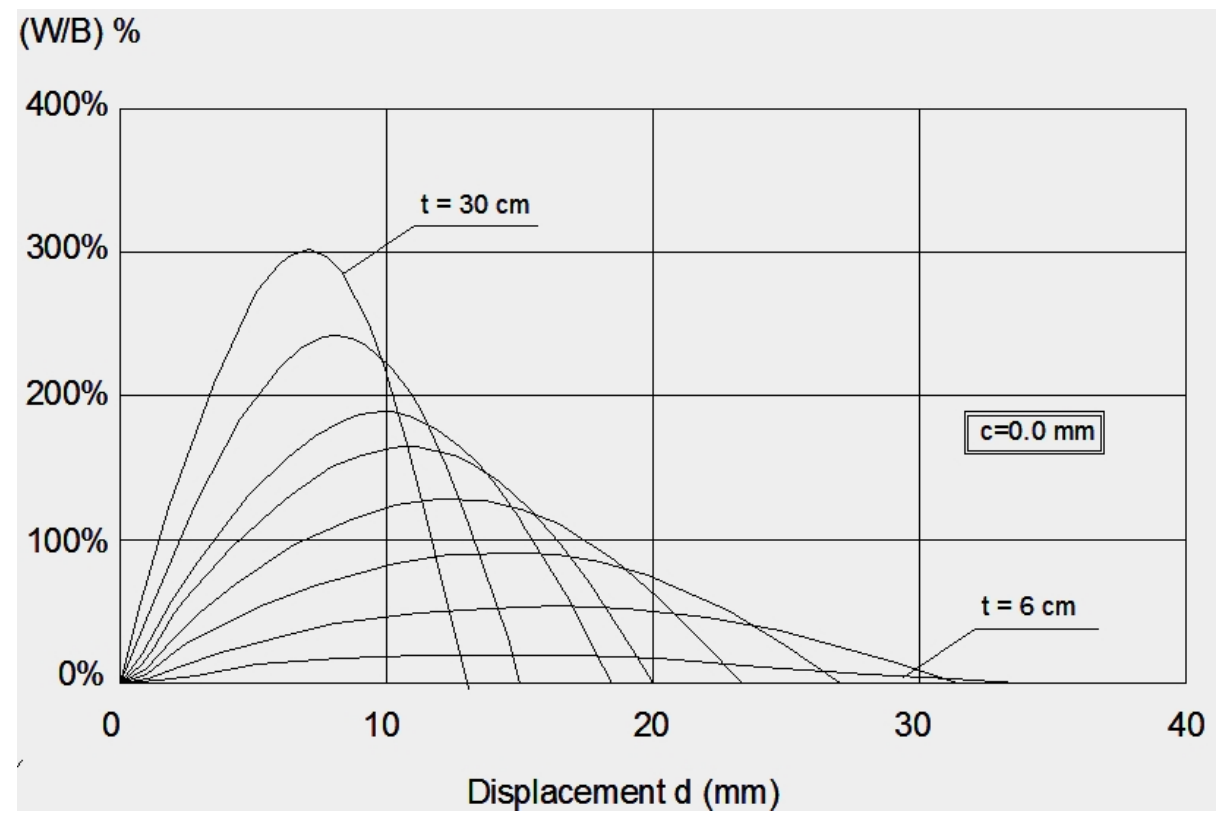

Fig. (7). Acceleration, in terms of (B/W), versus displacement $\delta$ at the midde of the wall for thickness $\mathrm{t}_{\theta}$ (in $\left.\mathrm{cm}\right) 6,8,12,15,18,20,25,30$ respectively (for cracked sections), fully fixed at top and bottom $(\mathrm{c}=0)$.

From eqs (18) and (19), $\chi$ and $\xi$ are determined, and $\mathrm{z}^{\prime}$ Fig. (5) can be calculated as

$\mathrm{z}^{\prime}=\frac{2 R_{2} * \xi+2 R_{1} *(2 \xi+\xi)}{6 R}$

b) From eqs (15) and (16), $\ddot{\alpha}_{\mathrm{w}, \mathrm{lim}}$ and $\delta_{\lim }$ (corresponding to the stage just before collapse) are calculated.

c) The same model can be used for the case showed in Fig. (5).

\section{ANALYTICAL RESULTS}

Analysis of the model corresponding to Fig. (1) has proved that it is practically impossible for a wall to collapse due to this mode, as the inter-story drift $\delta$ required exceeds many times the limit defined by the codes of practice. Such values for $\delta$ would have caused severe damage to the main frame on the structure considered, as well as to the walls in the perpendicular direction. This is the main reason why no damage of this type has been ever reported.

Parametric analysis associated with the models shown in Figs. (3 and 4) has been carried out for common wall construction practices in Greece, using measured value of uniaxial masonry compressive strength $\mathrm{f}_{\mathrm{cw}}=18 \mathrm{MPa}$, corresponding to "firm" type of construction (c=0, eqs. 5,6). Results for a wall segment with a width of $t=9 \mathrm{~cm}$ are graphically presented in Fig. (7). Focusing on the inelastic part of the diagram, a series of results are presented in Fig. (8), 


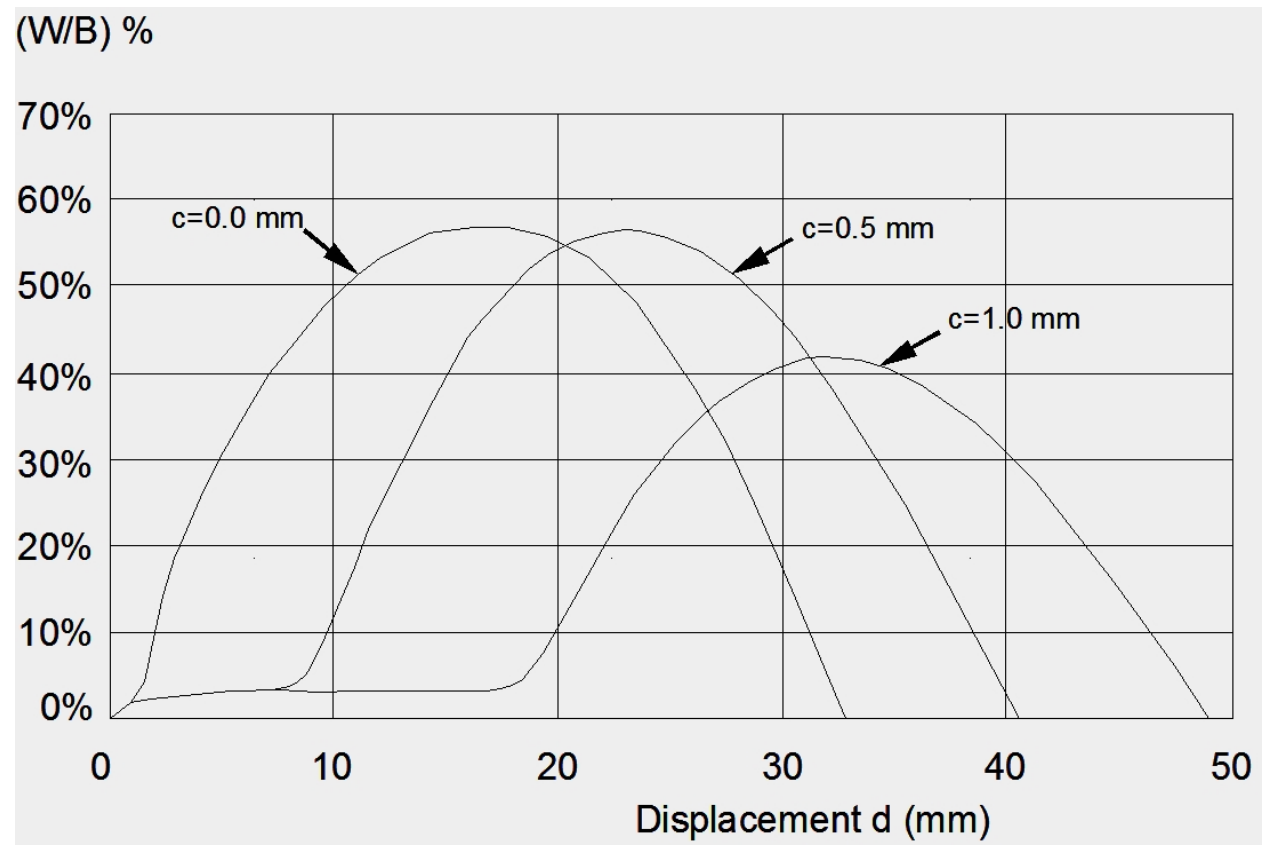

Fig. (8). Influence of parameter $c$ to the lateral behaviour of walls $\left(\mathrm{t}_{0}=9 \mathrm{~cm}\right)$.

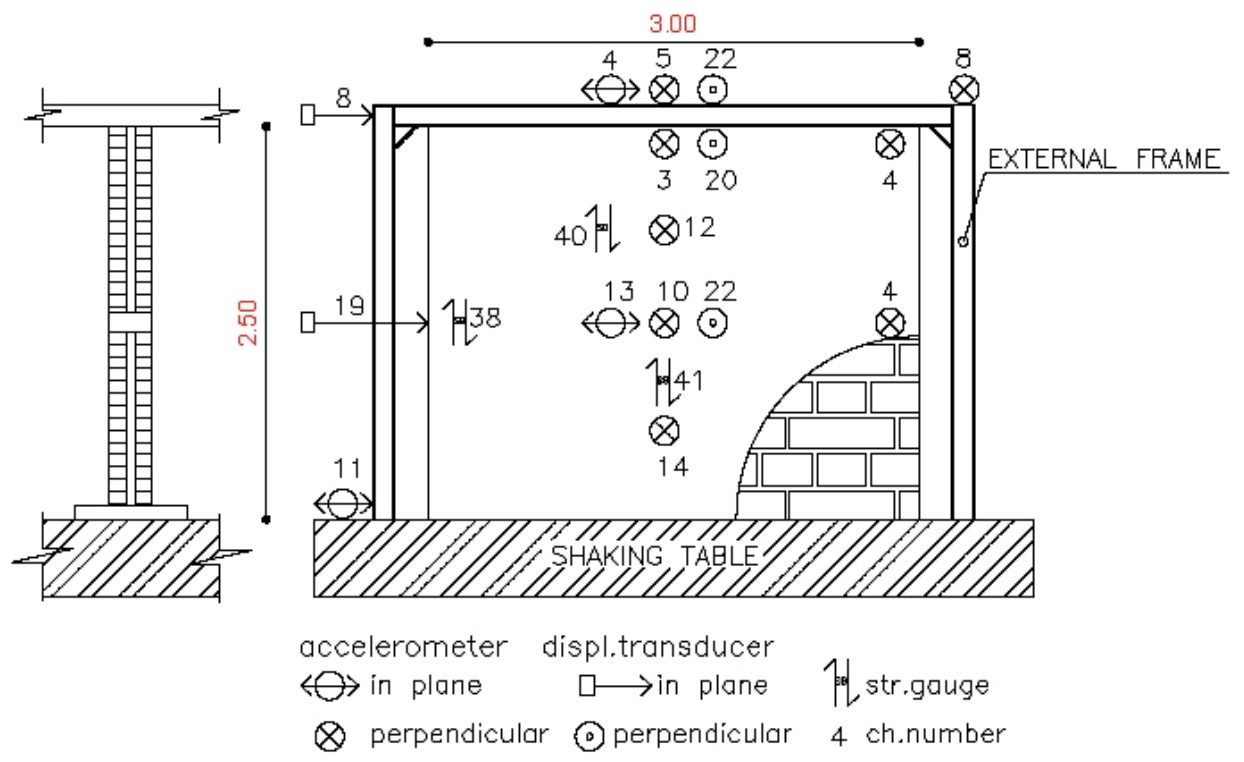

Fig. (9). Experimental set-up for out of plane response off wall (Carydis et al. [24]).

showing that the segment width significantly affects the minimum acceleration required for the lateral collapse of the wall.

In Fig. (8), the influence of parameter $c$ (representing inproper construction, creep, etc) on the lateral behaviour of the walls is illustrated. It is shown that even $1 \mathrm{~mm}$ of shrinkage can decrease the capacity or the wall more than the one third of its initial value. Most important is that, in such cases, cracks are formed at very low values of acceleration (of the order of $0.04 \mathrm{~g}$, which corresponds to even smaller values of PGA, of the order of $0.01-0.02 \mathrm{~g}$, that means very frequent earthquakes.

Analytical predictions are also compared to experimental data obtained by Carydis et al. [24] The experimental set-up employed in this investigation is presented in Fig. (9). The eigen-period of the wall alone was measured at $\mathrm{T}=0.268 \mathrm{sec}$, while for the coupled system it was measured at $\mathrm{T}=0.277 \mathrm{~s}$. When subjecting the specimen to a maximum value of base acceleration $\alpha=0.05 \mathrm{~g}$ shown in Table 1 the following values have been recorded.

During testing the wall specimen suffered extensive cracking in the horizontal direction (at the top and bottom as well at the middle of its height), but did not appear to reach an unstable position and therefore did not overturn (collapse). This is in direct agreement with the analytical predictions of the proposed model showed in Fig. (6). Furthermore the predictions of the proposed model confirm the available data $[26,29,30]$ describing the out-of-plane response of ma- 
Table 1. Experimental values by Carydis et al. [24].

\begin{tabular}{|l|l|l|l|l|l|}
\hline $\begin{array}{l}\text { TYPE OF BASE EX- } \\
\text { CITATION }\end{array}$ & $\begin{array}{l}\text { ACCELERATION } \\
\text { AT TOP OF FRAME } \\
\text { (a) }\end{array}$ & $\begin{array}{l}\text { ACCELERATION AT } \\
\text { MID-DLE OF THE } \\
\text { WALL (b) }\end{array}$ & $\begin{array}{l}\text { “MEAN } \\
\text { ACCELE- } \\
\text { RATION" } \\
(\mathbf{c})=[\mathbf{0 . 0 5 +} \\
+(\mathbf{a})+\mathbf{2}(\mathbf{b})] / 4\end{array}$ & $\begin{array}{l}\text { DISPLACE MENT } \\
\text { AT TOP OF FR- } \\
\text { AME }\end{array}$ & $\begin{array}{l}\text { DISPLACEME-NT AT } \\
\text { MID-DLE OF THE } \\
\text { WALL }\end{array}$ \\
\hline \hline Sinusoidal, T=0.21s & $0.20 \mathrm{~g}$ & $0.45 \mathrm{~g}$ & $0.29 \mathrm{~g}$ & $2.5 \mathrm{~mm}$ & $2.0 \mathrm{~mm}$ \\
\hline $\begin{array}{l}\text { Sinusoidal, T= }=0.27 \mathrm{~s} \\
\text { (Resonance) }\end{array}$ & $0.22 \mathrm{~g}$ & $0.80 \mathrm{~g}$ & $0.49 \mathrm{~g}$ & $8.0 \mathrm{~mm}$ & $7.4 \mathrm{~mm}$ \\
\hline
\end{tabular}

sonry infill walls when subjected to lateral loading. This agreement between analytical and experimental predictions shows the ability of the proposed model to provide realistic predictions regarding the out of plane motion of the infill wall.

\section{CONCLUDING REMARKS}

Based on the comparison of the experimental and the numerical investigation it appears that the proposed model is capable of realistically predicting the behavior and loadcarrying capacity of the infill walls in the out of plain direction. However it should be noted that additional analytical, experimental and numerical work is required to fully verify the its accuracy.

The proposed model can be employed to simulate the behavior of the infill walls within frames structures during structural analysis by providing a failure criterion against out-of-plain motion. In doing so it can improve the predictions of existing strut models currently used to model only the in-plane behavior of infill walls. This will allow for more accurate predictions concerning the effect of the infill walls on the overall structural response of $\mathrm{RC}$ frame structures under static and earthquake loading conditions. In doing so, the analysis will be able to provide better predictions regarding the redistribution of the internal actions developing within the structural elements of the frame due to their interaction with the infill walls. Such predictions would allow one to safeguard against the development of stress concentrations which in turn can result in localized damage or even brittle failure of certain main (load-baring) structural elements (i.e. columns, beams, joints, walls) which have a detrimental effect on the overall structural response.

\section{CONFLICT OF INTEREST}

The author confirm that this article content has no conflicts of interest.

\section{ACKNOWLEDGEMENT}

Declared none.

\section{REFERENCES}

[1] EN 1998-1, Eurocode 8: Design of structures for earthquake resistance - Part 1: General rules, seismic actions and rules for buildings - Part 3: Assessment and retrofitting of buildings, 2004.

[2] B.S. Smith, "Behavior of square infilled frames", J. Struct. Div. ASCE., vol. ST1, pp. 381-403, 1966.

[3] B.S. Smith, and C. Carter, "A method of analysis for infilled frames", Proc. Inst. Civil Eng., vol. 44, pp. 31-48, 1969.

[4] A.W. Page, P. W. Kleeman, and M. Dhanasekar, "An In-Plane Finite Element Analysis Model for Brick Masonry", In: Proc. of a session held in conjunction with Structures Congress'85, Chicago, Ill, 1985, p.1-18.

[5] A.B. Mehrabi, P.B. Shing, M. Schuller, and J. Noland, "Experimental evaluation of masonry-infilled RC frames", J. Struct. Eng. ASCE., vol. 122, no. 3, 228-237, 1996.

[6] S. G. Buonopane, and R. N. White, "Pseudodynamic testing of masonry infilled reinforced concrete frame", J. Struct. Eng. ASCE., vol. 125 , no. 6 , pp. $578-589,1999$.

[7] T. C. Liauw, and K. H. Kwan, "Nonlinear behaviour of nonintegral infilled frames", Comput.Instruct., vol. 18, pp. 551-560, 1984.

[8] M. Dhanasekar, and A.W. Page, "Influence of brick masonry infill properties on the behaviour of infilled frames", Proc. Inst. Civil Eng. Lond., Part 2, vol. 81, pp. 593-605, 1986.

[9] A. Saneinejad, and B. Hobbs, "Inelastic design of infilled frames", J. Struct. Eng. ASCE., vol. 121, no. 4, pp. 634-650, 1995.

[10] C.A. Syrmakezis, and P.G. Asteris, "Influence of infilled walls with openings to the seismic response of plane frames", In: $C D$ Proceedings of the Ninth Canadian Masonry Symposium, 4th-6th, June, 2001, Fredericton, New Brunswick, Canada, 2001.

[11] P. G. Asteris, "Lateral stiffness of brick masonry infilled plane frames", J. Struct. Eng. ASCE., vol. 129, no. 8, pp. 1071-1079, 2003.

[12] P.G. Asteris, "Finite element micro-modeling of infilled frames", Elect. J. Struct. Eng., vol. 8, pp.1-11, 2008.

[13] H. A. Moghaddam, and P. J. Dowling, "The State of the Art in Infilled Frames", ESEE Research Report No. 87-2, Civil Eng. Department, Imperial College of Science and Technology, London, U.K. 1987.

[14] P.G. Asteris, S.T. Antoniou, D.S. Sophianopoulos, and C.Z. Chrysostomou, "Mathematical macromodelling of infilled frames: state of the art", J. Struct. Eng. ASCE., vol. 137, no. 12, pp. 1508-1517, 2011.

[15] P.G. Asteris, D.J. Kakaletsis, C.Z. Chrysostomou, and E.E. Smyrou, "Failure modes of infilled frames", Elect. J. Struct. Eng., vol.11, no. 1, pp.11-20, 2011.

[16] D. Guney, A.O. Kuruşcu, and M. Vatan, "Optimizing the organization of infill walls in order to improve the earthquake response," In: COST Action C26: Urban Habitat Constructions Under Catastrophic Events, 16-18 September 2010, Naples, Italy, 2010.

[17] D. Guney, and E. Aydin, "The nonlinear effect of infill walls stiffness to prevent soft story collapse of RC Structures," Open Construct. Build. Technol. J., vol. 6, 2012. (in press)

[18] H. A. Moghaddam, "Lateral load behavior of masonry infilled steel frames with repair and retrofit", J. Struct. Eng. ASCE., vol. 130, no. 1, pp. 56-63, 2004.

[19] A. Madan, A. M. Reinhorn, J. B. Mander, and R. E. Valles, "Modeling of masonry infill panels for structural analysis", J. Struct. Eng. ASCE., vol. 123, no. 10, pp. 1295-1302, 1997.

[20] F. J. Crisafulli, A. J. Carr, and R. Park, "Analytical modelling of infilled frame structures-a general review", Bull. NZSEE, vol. 33, no. 1, pp. 30-47, 2000.

[21] P.G. Asteris, and D.M. Cotsovos, "Effect of concrete infill panels on the overall structural response of RC frames", Open Construct. Build. Technol. J., vol. 6, pp. 164-181, 2012.

[22] R. Angel, D. Abrams, D. Shapiro, J. Uzarski, and M. Webster, "Behavior of Reinforced Concrete Frames with Masonry Infills," Technical Report UILU-ENG-94-2005, Department of Civil Engineering, University of Illinois at Urbana-Champaign, IL, 1994. 
[23] FEMA-306, "Evaluation of Earthquake damaged concrete and masonry wall buildings - Basic Procedures manual", Federal Emergency Management Agency: Washington, D.C. 1999.

[24] P. Carydis, E. Vougioukas, C. Mouzakis, and I. Taflambas, "Experimental response of infilled frames to out-of-plane seismic motions," In: 2nd Greek Congress for Earthquake Engineering, Greece pp.75-84, 2001. (in Greek).

[25] C.S. Meisl, K.J. Elwood, and C.E. Ventura, "Shake table tests on the out-of-plane response of unreinforced masonry walls", Can. J. Civil Eng., vol. 34, no. 11, pp. 1381-1392, 2007.

[26] M. Liu, Y. Cheng, and X Liu, "Shaking table test on out-of-plane stability of infill masonry wall", Trans. Tianjin. Univ., vol. 17, no. 2, pp. 125-131, 2011.
[27] P.G. Carydis, N.R. Tilford, G. Brandow, and J.O. Jirsa, The Central Greece Earthquakes of February-March 1981, National Research Council, Earthquake Engineering Research Institute, National Academies: Washington DC, 1982, p.160.

[28] R. Vicente, J.A.R. Mendes da Silva, H. Varum, H. Rodrigues, and A. Costa, "Masonry Enclosure Walls: Lessons learnt from the recent Abruzzo earthquake", paper 1224, 14 ECEE: Ohrid, 2010.

[29] BASHANDY T-R, "Behavior Of Reinforced Concrete Infilled Frames Under Dynamic Loading", Doctoral Thesis. The University Of Texas: Austin, 1995.

[30] M. Mohammadi, V. Akrami, and R. Mohammadi, "Experimental and analytical studies onthe infilled frames with frictional sliding fuses," J. Am. Soc. Energy Eng., vol. 11, no. 4, pp. 205-213, 2010.

Received: December 29, 2011

() E. Vougioukas; Licensee Bentham Open.

This is an open access article licensed under the terms of the Creative Commons Attribution Non-Commercial License (http://creativecommons.org/licenses/by-nc/3.0/) which permits unrestricted, non-commercial use, distribution and reproduction in any medium, provided the work is properly cited. 